DOI: https://doi.org/10.35699/2237-5864.2018.2452

\title{
USO DO MAPA CONCEITUAL COMO FERRAMENTA DE ENSINO-APRENDIZAGEM NO DESENVOLVIMENTO DO TRABALHO DE CONCLUSÃO DE CURSO
}

Jaqueline Almeida Guimarães Barbosa ${ }^{1}$ Selme Silqueira de Matos $^{1}$

\section{RESUMO}

A realização do trabalho de conclusão de curso (TCC) é um desafio para discentes de graduação. Este estudo teve como objetivo relatar a experiência do uso de mapas conceituais como ferramenta de ensino-aprendizagem no desenvolvimento do TCC na graduação em Enfermagem. Resultados: a elaboração do mapa conceitual sobre o TCC a ser desenvolvido propiciou aos discentes a organização de ideias e a autopercepção de alinhamentos necessários a fim de se chegar à coerência exigida entre as etapas que compõem o estudo científico. A ferramenta favoreceu a visualização do processo de pesquisa como um todo, bem como a compreensão das relações entre as partes que o compõem. Conclusão: o mapa conceitual mostrou-se uma estratégia efetiva no desenvolvimento do TCC, além de servir como um instrumento de avaliação do aluno por parte do docente, uma vez que reflete todo o raciocínio do discente.

Palavras-chave: Mapa conceitual. Metodologia de ensino. Metodologia da aprendizagem. Educação em Enfermagem.

\footnotetext{
${ }^{1}$ Escola de Enfermagem, Universidade Federal de Minas Gerais (UFMG), Belo Horizonte, MG, Brasil.
} 


\title{
USE OF THE CONCEPT MAP AS A TOOL FOR TEACHING-LEARNING IN THE DEVELOPMENT OF THE UNDERGRADUATE THESIS
}

\author{
Jaqueline Almeida Guimarães Barbosa \\ Selme Silqueira de Matos
}

\begin{abstract}
The accomplishment of the undergraduate thesis is a challange for students. This study was aimed to report the experience of the use of conceptual maps as a teaching tool in the development of undergraduate thesis in the Nursing course. Results: the design of the conceptual map about undergraduate thesis to be developed provided the students with the organization of ideas and with the self-perception of necessary alignments, with a view to achieving the coherence and cohesion required among the stages that comprise the scientific study. The tool fostered the visualization of the research process as a whole, as well as the understanding of the relationships among the parts that comprise it. Conclusion: the conceptual map has proved to be an effective strategy in the development of undergraduate thesis, besides operating as an instrument for the teacher to assess the student, as it reflects the whole reasoning of the student.
\end{abstract}

Keywords: Concept map. Teaching methodology. Learning methodology. Education in Nursing. 


\section{INTRODUÇÃO}

A elaboração do Trabalho de Conclusão de Curso (TCC) é condição obrigatória para a conclusão dos cursos de graduação, entre os quais se inclui a Enfermagem, conforme descrito na Resolução do Conselho Nacional de Educação/Câmara de Educação Superior (CNE/CES) $\mathrm{n}^{\circ}$ 3, de 7 de novembro de 2001, que institui as Diretrizes Curriculares Nacionais do Curso de Graduação em Enfermagem (BRASIL, 2001). Na Universidade Federal de Minas Gerais (UFMG), na graduação em Enfermagem, a preparação para a construção do TCC se inicia com a disciplina de Metodologia Científica, oferecida no primeiro período, quando são dadas as primeiras diretivas acerca da produção científica, com ênfase nos aspectos metodológicos.

No sexto período é ofertada a disciplina Elaboração de Projeto de Pesquisa. Nela são abordadas todas as etapas da construção de um projeto de pesquisa, e os discentes são instigados a elaborar um projeto de pesquisa em grupo, como exercício, uma vez que é uma atividade coletiva, não sendo ainda o trabalho final que desenvolverão no TCC. Nesse momento eles aprendem, entre outros, os requisitos éticos e legais requeridos na realização de pesquisas científicas e as diferentes metodologias possíveis de serem empregadas nas investigações.

Dando continuidade à preparação do aluno para o TCC, no sétimo período acontece a disciplina Seminário de Integração III, obrigatória, que tem como objetivo auxiliar o discente na estruturação do estudo científico que configurará o seu TCC. Nesse momento, ele deve ser capaz de postular com clareza o seu problema de pesquisa e seus objetivos, o que é feito em parceria com o professor escolhido pelo aluno para ser o orientador do TCC. Além disso, a disciplina propicia a reflexão sobre a metodologia a ser utilizada, avaliando sua adequação aos objetivos e sua viabilidade, considerando o tempo que o aluno dispõe para a realização do trabalho. A disciplina tem ainda, como finalidade, dentro das reflexões e das discussões que propicia, articular os conteúdos do currículo com as Dimensões do Cuidado de Enfermagem (Assistência, Educação, Pesquisa e Gestão) e com as competências desenvolvidas no percurso formativo.

Posteriormente os discentes continuam o desenvolvimento do TCC com seus respectivos orientadores, ao longo do oitavo e nono períodos, quando podem dar seguimento aos trâmites éticos e legais necessários à realização do estudo, bem como realizar a coleta e a análise dos dados, além da discussão dos resultados. No décimo período, o último da graduação, eles finalizam o estudo e apresentam o TCC para uma banca examinadora, a qual realiza a avaliação 
do trabalho, deliberando pela aprovação ou não do aluno. Cabe citar que na graduação em Enfermagem na UFMG é permitido desenvolver o TCC de forma individualizada ou em dupla.

Com a finalidade de auxiliar o aluno no desenvolvimento do TCC, optou-se pela utilização dos Mapas Conceituais (MCs) como recurso metodológico a ser adotado na disciplina. O MC é uma ferramenta elaborada por Joseph Novak, em 1970, que surgiu como estratégia facilitadora de uma aprendizagem significativa. É utilizado como dispositivo pedagógico que parte do pressuposto de que sua utilização estimula a estruturação e o arquivamento de conteúdos pelos alunos a partir da inter-relação entre conceitos (CARABETTA JÚNIOR, 2013; NOVAK, 1982). O MC configura-se, assim, como um diagrama que indica as relações existentes entre conceitos ou palavras que são usados para representá-los. Esses diagramas buscam transmitir os significados ou as relações significativas, podendo transmitir hierarquias conceituais. 0 enfoque no MC não está em classificar os conceitos, mas sim em suas relações, sendo que os conceitos contextualmente mais importantes devem ficar mais centralizados.

O fato de os conceitos estarem unidos por uma linha mostra a existência da relação entre eles. Setas podem ser usadas, mostrando o sentido de direção, o que não é, todavia, uma obrigatoriedade. Uma ou duas palavras-chave escritas sobre essa linha podem ser suficientes para explicar a natureza dessa relação, sendo importante que essas palavras sejam colocadas para evidenciar o significado da relação conceitual. Contudo, a elaboração do diagrama por si só não é suficiente para tornar os MCs autoexplicativos. Eles requerem sempre explicação por parte de quem os elaborou, que, ao explicá-los, externaliza seus significados (CARABETTA JÚNIOR, 2013; NOVAK, 1982).

A utilização dos mapas tem se mostrado uma alternativa favorecedora da aprendizagem autônoma e vem sendo estimulada nos cursos de graduação, em diferentes disciplinas, e também na Enfermagem (DRAGANOV; SANNA, 2015). Todavia, a literatura é escassa em publicações que abordam a aplicação do recurso no ensino da graduação em Enfermagem, não tendo sido encontrados estudos acerca de sua aplicabilidade para a construção do TCC. Esse contexto motivou a realização desse trabalho, o qual visa contribuir com outros profissionais que queiram adotar essa ferramenta em suas disciplinas e também como recurso que pode favorecer o desenvolvimento do TCC pelos discentes. Assim, o objetivo do estudo foi relatar a experiência do uso de MCs como ferramenta de ensino-aprendizagem no desenvolvimento do TCC na graduação em Enfermagem. 
No primeiro momento é dado o contexto da disciplina na qual o mapa conceitual foi utilizado e sua organização. Num segundo momento são apresentados exemplos de mapas elaborados pelos alunos e de como eles são apresentados ao final da disciplina. Posteriormente são colocados relatos dos alunos sobre o uso desse recurso. Ao final são comentadas as especificidades da aplicação dessa ferramenta para auxiliar o desenvolvimento do TCC.

\section{RESULTADOS E DISCUSSÃO}

\section{Contexto da disciplina em que a ferramenta do Mapa Conceitual foi utilizada}

A disciplina Seminário de Integração III tem 15 horas de carga horária teórico-prática, sendo distribuídas em quatro encontros. Na primeira aula, com duração de 4 horas, inicialmente ocorre a explanação da ementa e dos objetivos da disciplina, com sua organização e formas de avaliação, bem como é apresentado o referencial teórico adotado. Em seguida, aborda-se a regulamentação do TCC no Curso, quando os discentes são orientados sobre os prazos e sobre o planejamento que devem ter, assim como sobre o protagonismo e a responsabilidade esperados nesse processo, para que a graduação possa ser concluída no tempo previsto, com o TCC defendido. Nesse momento, reforça-se a necessidade de os futuros profissionais estarem preparados para saber fazer pesquisa científica, tendo em vista sua importância para o aprimoramento da prática profissional. Além disso, é feita uma discussão acerca das diferentes áreas já estudadas pelos alunos no curso até o momento e das variadas possibilidades de temas a serem investigados de forma aprofundada no TCC, com o intuito de ajudá-los na definição da temática a ser debruçada.

Posteriormente, ainda nesse primeiro encontro, os alunos são convidados a explanarem a área em que têm maior interesse em estudar e a fazerem um "brainstorming", termo este que significa provocar uma "tempestade de ideias" sobre os conteúdos que englobam a área, ou seja, deixar aflorar tudo o que Ihes vem à cabeça sobre a temática. Essa dinâmica tem o intuito de favorecer aos discentes vislumbrar uma diversidade de problemas de pesquisa possíveis, dentro da temática escolhida.

Ato contínuo, cada aluno recebeu um artigo científico e foi desafiado a identificar de qual problema de pesquisa originou o desenvolvimento do trabalho, avaliando a coerência entre o problema, o objetivo e a metodologia utilizados no artigo. Nesse momento, constataram- 
se as dificuldades que os discentes encontram para identificar e compreender o problema de pesquisa e também sobre as inter-relações entre as fases que compreendem a pesquisa científica. A atividade mostrou-se, assim, uma contribuição para a elucidação desses aspectos.

Ainda nesse primeiro encontro ocorre a abordagem sobre o uso do MC como ferramenta de ensino-aprendizagem e como o recurso a ser adotado favorece o desenvolvimento do TCC, quando os discentes são desafiados a esboçarem o trabalho almejado para o TCC por meio do mapa conceitual, apresentação a se realizar no último encontro. Salienta-se que o aluno teve um período de mais de 30 dias para desenvolver seu mapa conceitual, uma vez que os encontros da disciplina ocorrem com espaçamento de 15 dias.

Cabe pontuar que não foi a primeira vez que os alunos tiveram contato com o recurso do MC, o qual foi também adotado na disciplina de Anatomia. Dessa forma, ocorre a recapitulação sobre o uso da ferramenta, quando os conceitos são retomados e o processo de elaboração do MC é ponderado, com os recursos eletrônicos disponíveis para auxiliar no processo. Os alunos podem contar com o software CmapTools, disponível para uso no laboratório de informática da Instituição. Eles também foram informados de que poderiam se utilizar de outros meios para elaborar o MC, e que fariam a apresentação do mapa construído para toda a turma ao final da disciplina.

A segunda data foi destinada a orientações individuais, agendadas com o professor da disciplina, quando o aluno tem a oportunidade de expor suas ideias iniciais do MC e tirar dúvidas. Além disso, nesse momento, os alunos são estimulados a apresentarem seus MCs a algum colega, numa atividade recíproca, a fim de verificarem o entendimento do trabalho pelos seus pares. Porém, observou-se que muitos ficaram receosos em mostrar o projeto aos colegas, o que acredita-se decorrer do medo de críticas por erros, apesar de manifestarem que esse momento seria importante para auxiliá-los no aprimoramento do MC.

Os dois últimos encontros destinaram-se à apresentação dos MCs pelos alunos para o professor e para a turma, que se comporta, nesse momento, como uma banca avaliadora, analisando a clareza e a coesão entre as partes do estudo científico a ser desenvolvido apresentado na forma de um MC. Os alunos ouvintes foram valorados nesse momento, inclusive pela contribuição que ofereceram àqueles que apresentaram os MCs. 


\section{O Seminário de apresentação dos Mapas Conceituais}

Cada aluno, ou dupla, teve 20 minutos para apresentar o MC e explicar cada fase da pesquisa a ser desenvolvida no TCC. Em seguida foram disponibilizados 10 minutos para ponderações do professor e dos ouvintes, ou seja, dos colegas que atuaram como banca. Trata-se de uma atividade que exige dos próprios ouvintes extrema atenção e capacidade de análise para pontuar seus comentários. Além disso, exige do discente que apresenta seu MC amplo domínio do tema a ser investigado, refletindo o empenho dedicado pelo aluno na realização da tarefa. Requer, ainda, habilidades para a comunicação em público, o que se observou ser um grande desafio para muitos estudantes, bem como uma oportunidade de preparação para a defesa do TCC, a acontecer ao final do curso.

\section{Exemplos de Mapas Conceituais elaborados pelos discentes}

A seguir são colocados exemplos de MCs apresentados na disciplina, com devida autorização dos autores. Cada qual aborda a temática escolhida pelo discente para ser estudada em parceria com seu orientador. Os alunos tiveram a liberdade de construir seu MC como quisessem, tendo sido, inclusive, estimulados a usarem a criatividade em prol de construir um MC compreensível e atrativo.

Os mapas foram apresentados em data show e explicados verbalmente pelos seus autores. A construção e a explanação dos MCs refletiam o nível de compreensão de cada aluno sobre o processo de pesquisa, deixando aflorar suas dúvidas e suas limitações até aquele momento. Ressalta-se aqui que o MC não é algo acabado, podendo e devendo ser revisto e reformulado conforme o discente vai amadurecendo seu pensamento, ou seja, ele poderia ser aprimorado mesmo após o término da disciplina Seminário de Integração III. Foi sugerido que cada versão fosse salva e que o discente fizesse a comparação e a observação da evolução do raciocínio ao longo do processo de elaboração do MC do TCC. A experiência nessa disciplina mostrou que, em média, cada aluno desenvolveu de 3 a 4 versões do $M C$ até chegar ao que foi apresentado no Seminário final. Selecionaram-se alguns MCs apresentados pelos discentes para ilustrar este relato: 
Mapa conceitual 1 - Temática da Assistência de Enfermagem a Crianças e Adolescentes

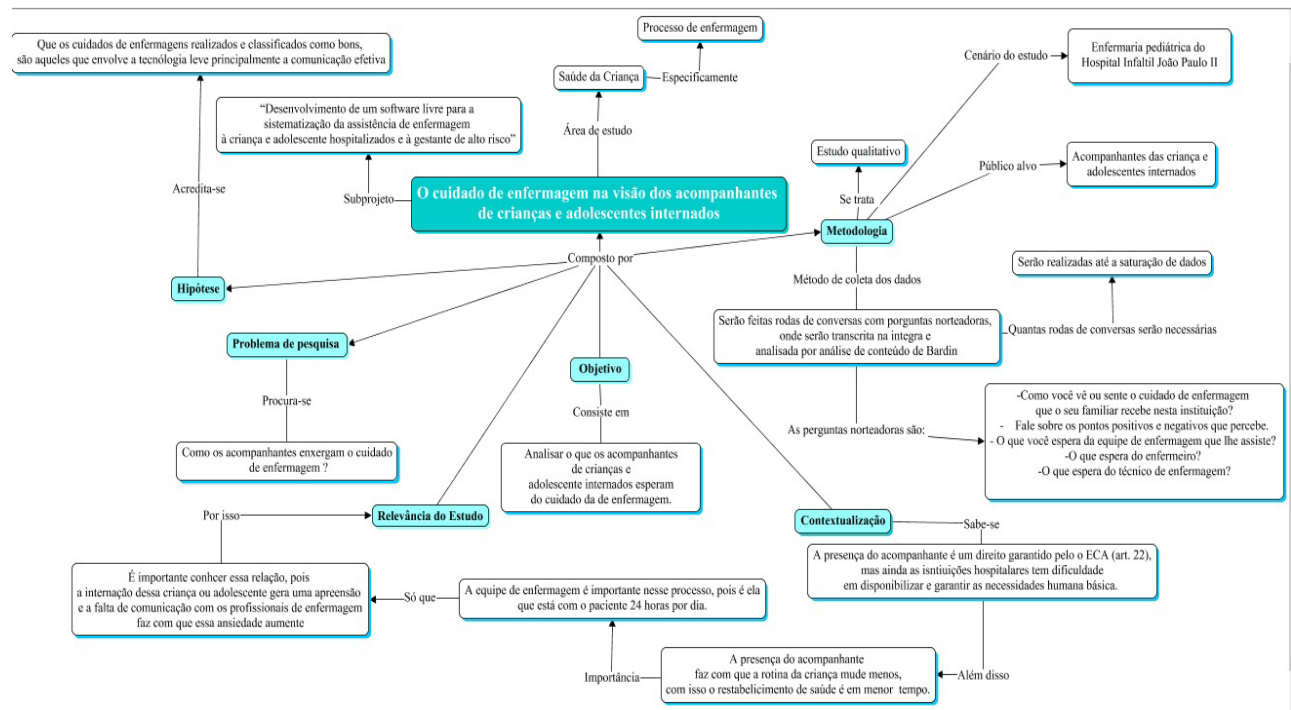

Fonte: dados do autor - mapa elaborado por discente da disciplina Seminário de Integração III, 2017.

\section{Mapa conceitual 2 - Temática da Assistência de Enfermagem em Terapia Intravenosa}

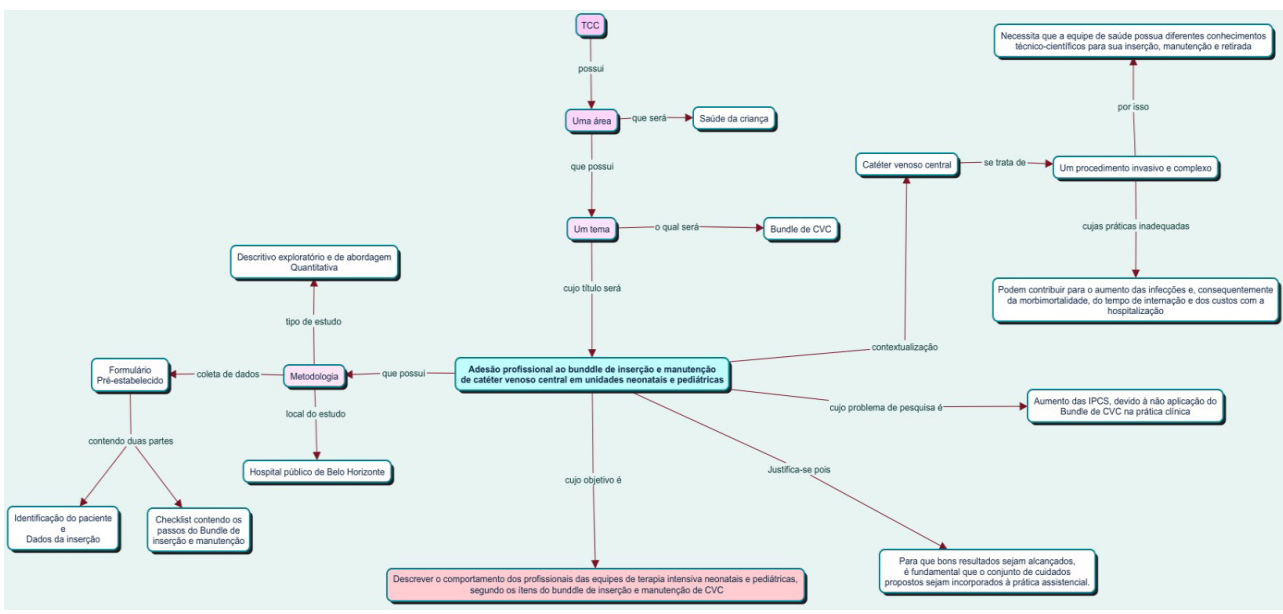

Fonte: dados do autor - mapa elaborado por discente da disciplina Seminário de Integração III, 2017. 
Mapa conceitual 3 - Temática da Assistência de Enfermagem à Saúde da Mulher

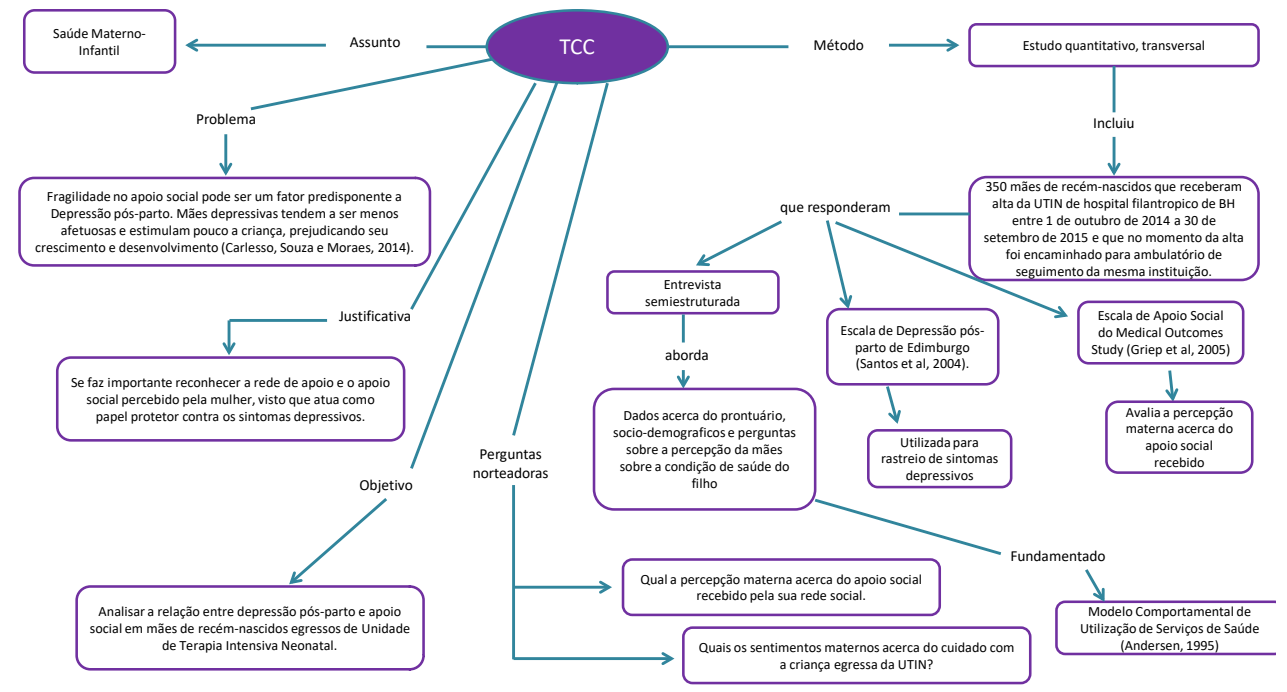

Fonte: dados do autor - mapa elaborado por discente da disciplina Seminário de Integração III, 2017.

Mapa conceitual 4 - Temática da Saúde do Trabalhador de Enfermagem

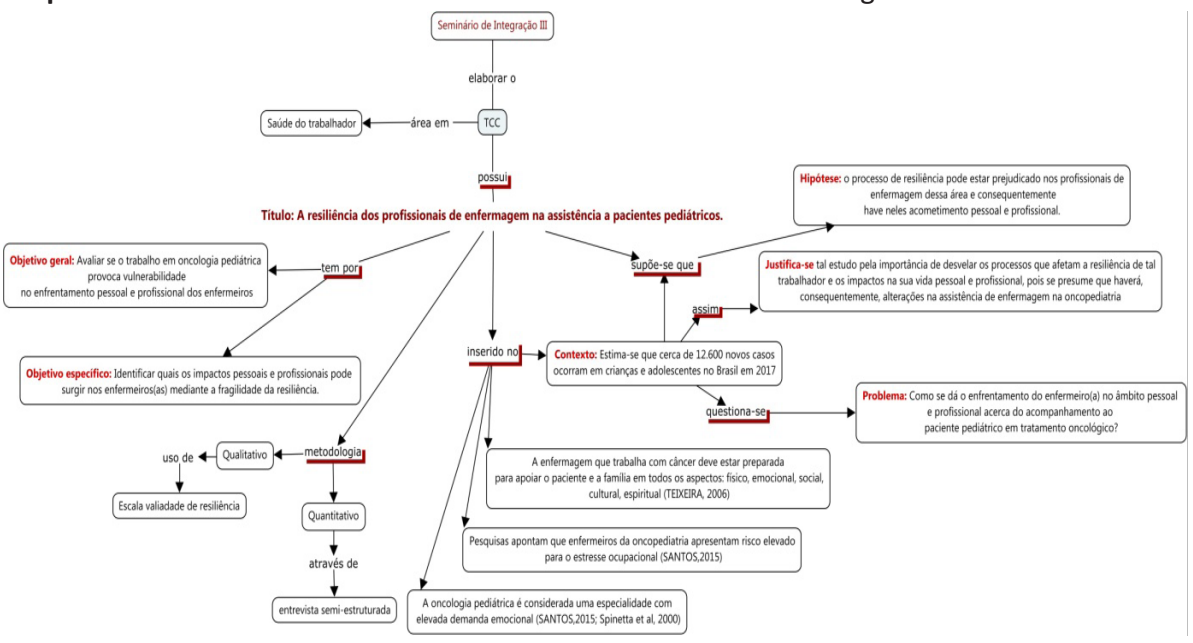

Fonte: dados do autor - mapa elaborado por discente da disciplina Seminário de Integração III, 2017. 
Mapa conceitual 5 - Temática da Assistência de Enfermagem em Saúde Coletiva

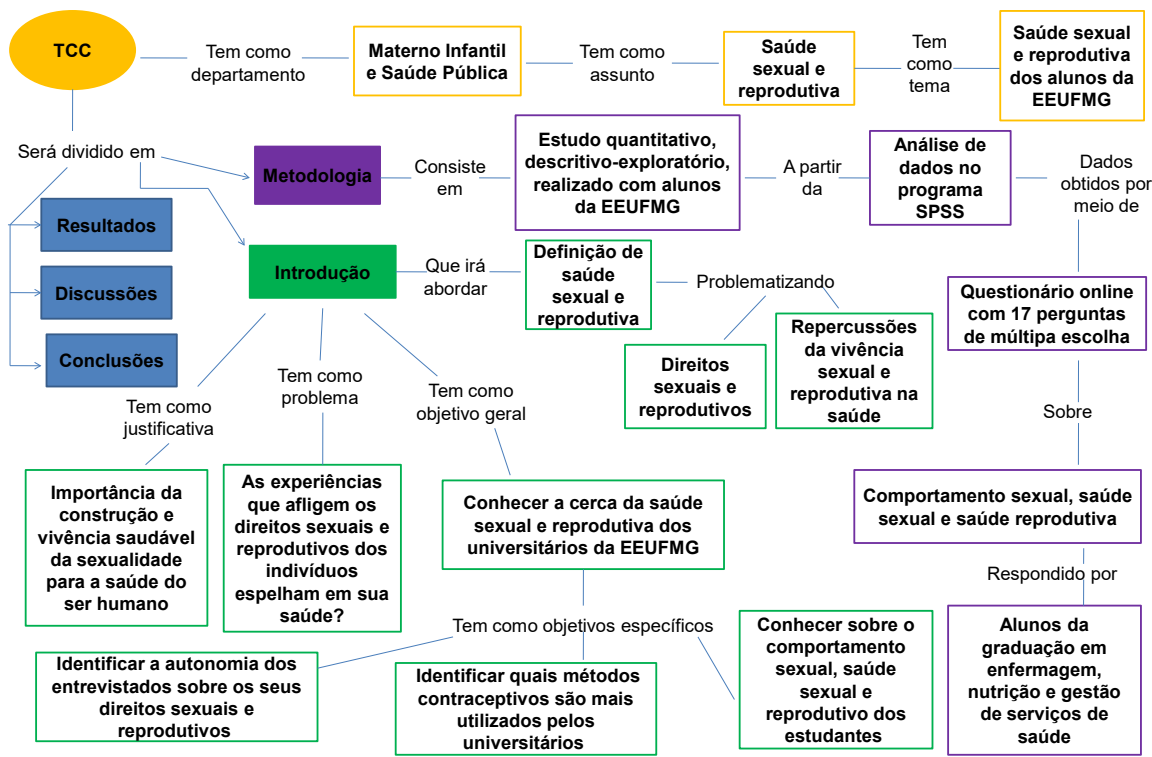

Fonte: dados do autor - mapa elaborado por discente da disciplina Seminário de Integração III, 2017.

A diversidade de formatos observada nos MCs apresentados refletem as inúmeras possibilidades de formatos que os diagramas podem tomar, a depender do interesse, da capacidade e da criatividade do aluno. Ao final da apresentação de cada MC ocorreu um debate, e contribuições eram colocadas por colegas, os quais também podiam solicitar esclarecimento de algum aspecto não totalmente compreendido ou que não havia sido dito na explanação verbal. Uma solicitação comum observada nos ouvintes estava em saber de onde nasceu o interesse em pesquisar aquele tema específico, o que foi explicado por cada autor.

Pontua-se, aqui, grandes dificuldades observadas para a apresentação do mapa conceitual em público, por parte de alguns alunos, o que se procurou apoiar e auxiliar de modo que os discentes pudessem superar as limitações existentes. Eles eram tranquilizados por se tratar de um momento de aprendizagem, e não de punições. Assim, todos apresentaram o seu MC em data show, com explanação verbal sobre o trabalho. Da mesma forma, todos avaliaram e foram avaliados pelos seus próprios pares, quando sugestões foram colocadas de forma 
respeitosa, sendo que a avaliação dos MCs apresentados pelos colegas mostrou-se um fator favorecedor da autocrítica do MC de cada um.

Por meio das apresentações dos MCs foi possível visualizar a clareza que o discente tinha do TCC que iria desenvolver e das limitações para seu desenvolvimento, o que servia de guia para que pudesse receber orientações individualizadas. Tomava-se nota de todos esses aspectos para um posterior feedback individualizado, caso fosse necessário, por parte do professor da disciplina.

A elaboração dos MCs mostrou-se uma estratégia realmente facilitadora de uma aprendizagem autônoma e significativa, mesmo tendo sido observado que os alunos poderiam aprimorar, ainda muito, os MCs apresentados. As relações entre os conceitos colocadas pelos alunos refletem o grau de compreensão destes sobre o processo de pesquisa como um todo, sendo que em alguns casos elas ficaram mais superficiais e em outras mais aprofundadas, refletindo o pensamento de cada um. Além disso, observou-se que o MC pode servir como um "guia" para o aluno na condução do desenrolar da sua pesquisa, ajudando-o a não se perder do objetivo central do estudo e da sequência necessária.

Conforme afirma Carabetta Júnior (2013), a aprendizagem acontece quando uma informação soma-se a conhecimentos pré-existentes na estrutura cognitiva dos sujeitos, sendo que as conexões vão se ampliando com o tempo, conforme a capacidade de abstração e generalização de cada um. Ao propiciar a integração e a relação entre as informações do texto e as palavraschave, o aluno atribui significado ao conteúdo com que está trabalhando, o que, sem o uso do recurso dos MCs, parece ser mais complexo e de difícil entendimento por eles. Além disso, a elaboração dos MCs propiciou o uso da criatividade e modificou o fazer pedagógico tradicional da sala de aula, saindo da transmissão passiva de informações do docente para o discente para uma atitude de tornar o aluno protagonista do próprio aprendizado (TARDIF, 2011).

\section{Percepção dos alunos sobre o uso de mapas conceituais}

Ao final da disciplina, os alunos foram convidados a se manifestar, caso quisessem, por meio de um relato escrito, acerca do uso dos MCs como estratégia metodológica de ensinoaprendizagem, com o objetivo de contribuir para o aprimoramento da disciplina. De maneira geral, as falas convergiram para uma avaliação positiva do uso desse recurso, que consideraram 
favorecer a visualização integral do estudo a ser desenvolvido e as relações entre as partes, apesar de não ser considerada uma ferramenta fácil de ser utilizada para a explanação do TCC:

Quando se inicia um projeto de pesquisa, torna-se complicado traçar metas, entender qual seu problema de pesquisa, por que este estudo se justifica, quais suas fortalezas e fragilidades. O MC se mostrou uma ótima ferramenta para entender meus objetivos e elucidar dúvidas quanto ao desenvolvimento do TCC. Ao transpor o projeto de pesquisa para o MC, foi possível enxergar a sua viabilidade. Além disso, a disciplina permitiu uma prévia da apresentação do TCC, quando pude contar com as considerações dos colegas que me auxiliaram a enxergar os erros e a efetivar as potencialidades do meu trabalho (J. B.).

Nesse relato é explicitado como o MC favoreceu a compreensão das fases da própria pesquisa pelos alunos e o aprendizado daquele que apresentava o $\mathrm{MC}$ com as críticas construtivas feitas pelos colegas que assistiram à apresentação.

Acho que o MC como estratégia de aprendizagem é uma ferramenta muito didática e a considero ideal. Devido ao fato de que é preciso organizar e representar as ideias e os conceitos com suas devidas correlações de maneira sintetizada e clara, a construção do mapa exige uma compreensão aprofundada do assunto que iremos tratar. Isso nos obriga a aprimorar ainda mais o nosso conhecimento para alcançar esse objetivo. Na minha experiência pessoal, ao iniciar a construção do mapa e ao pedir a opinião dos colegas, percebia que era difícil para eles entenderem o que eu queria dizer em determinado momento. No entanto, quando reelaborado com maior domínio do estudo, foi notada uma diferença significativa da compreensão deles. Isto demonstra que a construção do mapa dá um feedback do que se sabe e incentiva diretamente o estudo. Além do mais, embora tenha tido cerca 25 a 30 apresentações de diferentes MCs na disciplina, consigo ainda me lembrar da maioria dos temas apresentados, pois a apresentação foi objetiva e esquematizada e em um curto intervalo de tempo (S. T.).

Essa fala ilustra que durante o processo de construção do MC os alunos precisam recorrer à literatura em vários momentos, ora para elucidarem seus conceitos centrais, ora para esclarecimentos sobre as fases da pesquisa científica, mostrando-se estimulador dos estudos de forma autônoma. Além disso, observou-se ter ocorrido aprendizagem decorrente da possibilidade de assistirem aos diferentes MCs feitos pelos colegas, o que os ajudou a refletir sobre o seu próprio MC. 
Tive o primeiro contato com mapas conceituais na disciplina de Anatomia Humana do ciclo básico do curso de Enfermagem. Porém, devido ao grau de dificuldade da disciplina, a experiência para mim não foi produtiva, nós tínhamos que fazer um mapa conceitual de cada parte do copo humano. Quando soube que teríamos que fazer o mapa na disciplina de Seminário de Integração, já fiquei apreensiva devido à experiência anterior, mas confesso que desta vez foi bastante diferente. A dificuldade maior que tive foi em relação à ferramenta, pois fazia as de anatomia manualmente. Agora era para fazermos eletronicamente. Para mim, o uso do mapa conceitual nessa disciplina foi positivo, pois contribuiu para que eu pudesse pensar o meu projeto de forma integral, e conseguisse mostrar aos meus colegas de forma clara e objetiva o passo a passo que eu viria a seguir (F. D.).

Reforça-se a natureza inacabada do MC, o qual está em constante processo de mudança e aperfeiçoamento, devendo ser visto, pois, com a característica de incompletude. Os conceitos se apoiam uns aos outros, relacionando-se mutuamente na construção das significações. A possibilidade de modificações frequentes em recursos eletrônicos vem a facilitar o processo.

No relato que se segue fica explícito que uma das dificuldades no uso dos mapas conceituais é a capacidade de síntese que o recurso exige do tema a ser abordado no TCC, o que, contudo, é reconhecido, posteriormente, como algo positivo.

Particularmente não gosto de MC. Além de serem trabalhosos de serem feitos, é uma atividade que não me desperta muito interesse. Para mim, o TCC é muito complexo para ser resumido em um mapa. Todavia, há uma grande oportunidade aí, que é o precioso poder de síntese. A síntese em todo momento é trabalhada através dessa metodologia, uma vez que ideias importantes e centrais devem ser priorizadas e configuradas de forma que haja sentido e conexão entre as mesmas no mapa. De todo modo, vejo o quanto avancei e estou avançando em minha capacidade de sintetizar, com isso, talvez não goste do MC devido a uma dificuldade minha, que está sendo superada (A. M.).

Constataram-se, em alguns casos, maiores dificuldades para a elaboração do MC, o que esteve relacionado ao fato de o aluno ainda não ter escolhido ou recebido ajuda do orientador do TCC por algum motivo, sendo que alguns tinham, até aquele momento, a definição da problemática a ser investigada. Da mesma forma, identificou-se que discentes que cursavam períodos mais avançados ou que participavam de grupos de pesquisa, como bolsistas de iniciação científica ou como voluntários, encontravam-se mais maduros e seguros para essa 
elaboração, refletindo os benefícios e o valor dessas atividades no meio acadêmico. Havia alunos que, no início da disciplina, não tinham nem ideia do tema que gostaria de estudar no seu TCC, e verificou-se que a disciplina foi um incentivo para que esse processo fosse iniciado e a busca pela interação com o orientador fosse desencadeada.

A ideia inicial na adoção do recurso do $\mathrm{MC}$ era fazer transparecer para o próprio aluno todo o planejamento do TCC a ser desenvolvido, sendo que a estratégia mostrou-se eficaz não só para essa finalidade, mas também para auxiliar o aluno no planejamento das ações necessárias, tendo a visão do todo e da relação entre as partes, sem perder de foco os conceitos principais do trabalho. Para a elaboração do mapa, faz-se necessária a reflexão e o raciocínio visando encontrar a coerência que um estudo científico deve ter. Ao ser colocado no papel e explanado de forma detalhada, o MC mostrou-se, ainda, um valioso instrumento avaliativo do discente por parte do docente, sendo recomendada sua aplicação não só para o desenvolvimento de TCC e na graduação em Enfermagem, mas para qualquer curso de graduação e em diferentes disciplinas.

\section{CONSIDERAÇÕES FINAIS}

A experiência com o uso do MC para o desenvolvimento do TCC mostrou-se significativa e capaz de favorecer o amadurecimento dos alunos para as questões metodológicas, que envolvem o processo de elaboração do trabalho científico. Apesar de inicialmente alguns alunos apresentarem grande ansiedade decorrente de indefinições quanto aos rumos da pesquisa, o uso dessa ferramenta propiciou a visualização do todo e das inter-relações entre as partes do estudo científico, favorecendo assim o processo de tomada de decisões. Além disso, a disciplina possibilitou um ensaio prático para a apresentação do TCC em público, tendo os próprios colegas atuando de forma similar a uma banca, mas sabendo ser ainda um momento de aprendizagem, sem punições decorrentes de erros ou fragilidades.

A experiência vivenciada permite afirmar que a ferramenta do mapa conceitual é eficaz para auxiliar alunos no desenvolvimento do TCC. A elaboração e a apresentação dos mapas configuram-se como uma metodologia ativa, na qual o aluno não tem como manter uma atitude passiva, requerendo seu protagonismo em um trabalho original. Configura-se, ainda, como valioso instrumento de avaliação ao evidenciar a síntese das ideias do aluno e suas relações, refletindo sua compreensão e seu raciocínio sobre o processo de pesquisa e o tema a ser investigado. 
Cabe pontuar que a elaboração do mapa conceitual não é uma tarefa simples e fácil. Sua utilização requer disponibilidade do professor para auxiliar os alunos. Sua elaboração exige como condição inicial amplo conhecimento do discente sobre o tema a ser estudado, para que o uso dessa ferramenta alcance seu objetivo.

Uma das limitações vivenciadas na experiência relatada foi o tempo curto em que a disciplina se desenvolveu, com apenas quatro encontros, e a dificuldade dos alunos em procurarem orientação individualizada, ora decorrente da limitação de tempo deles próprios ou de seus orientadores, ora por timidez ou receio em buscar ajuda.

O MC mostrou-se propiciador do desenvolvimento da autonomia da própria aprendizagem. Espera-se que o discente aproveite esse recurso para outras finalidades ao longo de sua formação acadêmica e também na sua atuação profissional, uma vez que essa ferramenta engloba caráter teórico, pedagógico e crítico-criativo, considerados aspectos fundamentais para o exercício da profissão.

\section{REFERÊNCIAS}

BRASIL. Ministério da Educação. Conselho Nacional de Educação. Câmara de Educação Superior. Resolução CNE/CES n 3, de 7 de nov. de 2001. Institui Diretrizes Curriculares Nacionais do curso de Graduação em Enfermagem. Diário Oficial da União, Brasília, 7 de nov. de 2001. Seção 1. p. 37. Disponível em: <http://portal.mec.gov.br/cne/arquivos/pdf/ CES03.pdf>. Acesso em: 21 out. 2018.

CARABETTA JÚNIOR, Valter. A utilização de mapas conceituais como recurso didático para a construção e a inter-relação de conceitos. Revista Brasileira de Educação Médica, São Paulo, v. 37, p. 441-447, 2013.

NOVAK, Joseph Donald. The Theory Underlaying Concept Maps and how to Construct Them. Disponível em: <https://web.stanford.edu/dept/SUSE/projects/ireport/articles/ concept_maps/The\%20Theory\%20Underlying\%20Concept\%20Maps.pdf>. Acesso em: 26 out. 2018.

DRAGANOV, Patrícia Bover; SANNA, Maria Cristina. Estratégia para incentivar o uso de mapas conceituais no processo de ensino e aprendizagem em enfermagem. Nursing, São Paulo, v. 18, n. 216, p. 1024-1029, 2015. 
TARDIF, Maurice. Saberes docentes e formação profissional. 12. ed. Petrópolis: Vozes, 2011.

\section{Jaqueline Almeida Guimarães Barbosa}

Doutora em Enfermagem pela Universidade Federal de Minas Gerais. Docente adjunta do Departamento de Enfermagem Básica do Curso de Enfermagem da UFMG. Realiza pesquisas nas áreas de Enfermagem Básica e Fundamental.

jaqueline@task.com.br

\section{Selme Silqueira de Matos}

Doutora em Enfermagem. Docente associada 1 do Departamento de Enfermagem Básica do curso de Enfermagem da UFMG. Realiza pesquisas nas áreas de Enfermagem Básica e Fundamental.

selmesilqueira@gmail.com 